\title{
Ser tia ou professora? Profissionalidade na educação infantil, um olhar sobre as representações de professores do segmento
}

\author{
Be an aunt or teacher? Professionality in early childhood education, a look at the \\ representations of segment teachers
}

Jeanny Meiry Sombra Silva ${ }^{1}$

\begin{abstract}
Resumo
Este artigo aborda um estudo realizado com quinze pedagogas concluintes de uma pósgraduação lato-sensu numa instituição de ensino superior em São Paulo. A coleta de dados foi realizada por meio de um grupo focal cujo objetivo foi buscar compreender como as professoras participantes do estudo se representam e como percebem as representações que a sociedade faz do trabalho do professor da educação infantil. Os dados foram analisados com base nos pressupostos da Análise de Conteúdo de Bardin (2016) e fundamentados em autores como Freire (1997, 2001), Jodelet (2001), Moscovici (2003), dentre outros. Os resultados revelam que as representações sociais sobre o trabalho do professor desse segmento interferem nas relações e nas práticas pedagógicas e que a profissionalização é um caminho para mudanças de concepções. $O$ estudo evidenciou também o desejo de reconhecimento da educação infantil como uma etapa da educação básica.
\end{abstract}

Palavras-chave: Representações sociais. Profissionalidade. Educação infantil.

\begin{abstract}
This article deals with a study carried out with fifteen pedagogues completing a latosensu postgraduate course at a higher education institution in São Paulo. Data collection was carried out through a focus group whose objective was to understand how the teachers participating in the study represent themselves and how they perceive the representations that society makes of the work of teachers in this segment. Data were analyzed based on Bardin's Content Analysis assumptions and based on authors such as Freire (1997, 2001), Jodelet (2001), Moscovici (2003), among others. The results reveal that social representations about the work of early childhood education teachers interfere in relationships and pedagogical practices and that professionalization is a way to change conceptions. The study also highlighted the desire to recognize early childhood education as a stage of basic education.
\end{abstract}

Keywords: Social representations. Professionalism. Early childhood education.

\footnotetext{
1 Doutora em Psicologia da Educação PUC-SP. Professora da Educação Básica e de Pós-Graduação na Uniĺtalo. Formadora contratada SME Coped - Educação Infantil. Monitora do Programa de Estudos PósGraduandos em Educação: Formação de Formadores PUC-SP. E-mail: jeanny.sombra@hotmail.com
} 


\section{Introdução}

A constituição da profissionalidade docente está associada às experiências pessoais e profissionais. É um processo dinâmico e contínuo que se desenvolve ao longo da vida e da carreira, nos diversos contextos sociais, institucionais e culturais que permeiam o exercício do magistério. $O$ termo profissionalidade pode ser entendido como "o conjunto de competências que um profissional deveria ter ou, ainda, o conjunto de competências reconhecidas socialmente como característica de uma profissão" (ALTET, PERRENOUD, PAQUAY, 2003, p. 235).

A profissionalidade, dessa forma concebida, encontra consonância no pensamento de Paulo Freire, educador que valoriza o contexto da profissão como lugar em que o professor se realiza na condição de sujeito inacabado, e como tal, busca (re)construir a sua trajetória profissional atrelada à sua essência humana: "Quanto mais me capacito como profissional, quanto mais sistematizo minhas experiências quanto mais utilizo do patrimônio de todos e ao qual todos devem servir, mais aumenta minha responsabilidade com o ser humano" (FREIRE, 1996, p. 20).

Nesse sentido, pensar a profissionalidade articulada ao contexto de ensino envolve pensar nos vários segmentos de atuação do professor. Para Freire (1997), um segmento que não pode ser descuidado (ou mesmo menosprezado), ao se tratar de desenvolvimento profissional, é o da educação infantil.

O trabalho na educação infantil é frequentemente compreendido, em nossa sociedade, como uma ocupação permeada por estereótipos, dentre eles: uma profissão feminina, que não necessita de conhecimentos específicos, uma vez que a mulher, naturalmente, possui capacidades suficientes para exercer esse tipo de atividade (KUHLMANN, 2007). De fato, o profissional da educação infantil, no Brasil, historicamente, foi se constituindo num cenário sem qualquer exigência de qualificação, o que traz consequências que ainda hoje tendem a influenciar as concepções acerca da docência nesse estrato educacional (AZEVEDO; SCHNETZELER, 2005).

Assim, as relações de gênero, a competência profissional e, principalmente, o modelo feminino marcadamente presente no trabalho com a educação infantil são dimensões que caracterizam as discussões acerca da profissionalidade no segmento. Isso, provavelmente, contribui para a constituição de uma representação social negativa do professor e do trabalho desenvolvido com crianças pequenas.

Considerando que as representações sociais são um traço constitutivo da identidade profissional, será discutido neste artigo um recorte de um estudo realizado com professoras de educação infantil cujo objetivo foi o de buscar compreender como essas profissionais se representam e como percebem as representações que a sociedade faz ao trabalho do professor desse segmento.

Os resultados analíticos que serão relatados e discutidos nos próximos tópicos 
contribuem com a atividade investigativa no campo da formação de educadores, na medida em que servem para problematizar aspectos sobre a construção e a incidência de representações sociais na formação e na profissionalidade docente, especialmente aquelas relativas aos professores de educação infantil.

\section{Representações sociais e trabalho docente: um diálogo entre a teoria de Moscovici e o pensamento de Paulo Freire}

Serge Moscovici e Paulo Freire foram pensadores contemporâneos. No pensamento de ambos é possível encontrar pressupostos teóricos convergentes no que concerne à formulação de um paradigma da mudança em contraponto a uma ciência da conformidade e da estabilidade. Freire (1983) pontua, com clareza, que:

\section{[...] mudança e estabilidade não são um "em si", algo separado ou independente da estrutura; não são um engano da percepção. Mudança e estabilidade resultam ambas da ação, do trabalho que o homem exerce sobre o mundo. Como um ser de práxis, o homem, ao responder aos desafios do mundo, cria seu mundo: o mundo histórico-cultural. O mundo de acontecimentos, de valores, de ideias, de instituições. Mundo da linguagem, dos sinais, dos significados, dos símbolos (Freire, 1983, p.46).}

Nos anos 1960, Moscovici, elabora a teoria das representações sociais, tomando por base, principalmente, a sociologia moderna de Émile Durkheim, que adota a expressão "representação coletiva" para designar o efeito coercitivo do social sobre o individual, na qual crenças e ideais persistem ao longo do tempo, determinando os valores da sociedade. Para Durkheim, as representações coletivas têm caráter estático fazem com que as sociedades se mantenham coesas, conservando e preservando as estruturas. A partir disso, Moscovici amplia a compreensão de Durkheim ao atribuir às representações sociais um caráter dinâmico - com interesse na inovação e mudança social. Para ele, o ser humano, a partir de suas experiências individuais e coletivas, constrói e reconstrói seus conceitos, crenças, ideais que, de forma inconsciente, se agregam a sua capacidade de pensar e criar sobre sua realidade, orientando comportamentos e práticas. Nessa perspectiva, a representação social é entendida como uma forma de conhecimento socialmente elaborada e partilhada, promovendo a construção de uma realidade comum a um conjunto social. Assim, as representações não apenas atuam diretamente sobre nossa maneira de pensar, mas prescrevem nossos comportamentos e práticas e, enquanto tal, possuem uma "força irresistível, envolvendo uma tradição que decreta o que deve ser pensado" (MOSCOVICl, 2003, p. 36). Isso implica considerar o senso comum na vida social, relacionando-o ao comportamento humano criador, numa determinada realidade que se constitui da experiência responsável pelo movimento de comunicação e cognição do indivíduo.

Para Moscovici os atos psíquicos (individuais) têm origens sociais: o pensamento, o senso comum e a ciência se misturam a um só tempo, na história e na cultura. A 


\section{-Revista de Iniciação à Docência, v.6, n.2, 2021- \\ Publicação: dezembro, 2021 - ISSN 2525-4332}

realidade é uma estrutura social em inter-relação com outras estruturas sociais. Ontologicamente, um ser que é ser para si torna-se um ser para o outro, dependente quando perde seu direito de decidir, seguindo prescrições e determinações sociais (o que Hegel chamou de consciência servil ou senhoril).

Desta maneira, se o senso comum, historicamente, atribui ao professor de educação infantil um papel paternalista, cuja função básica se restringe a cuidar de bebês e crianças, isso significa que esse imaginário social condiciona a ação desse profissional? A resposta é “Não", pois, conforme Moscovici (1978), representar uma coisa não implica reprodução, mas reconstituição, inovação e mudança.

A articulação entre linguagem e representação consolida as razões das escolhas e das ações assumidas pelo sujeito social, provocando opiniões e atitudes diante do objeto. Por isso, as representações são sociais, não porque o sujeito é social, mas pela função que elas desempenham para organizar as condutas e a comunicação social - nas palavras de Moscovici (1978):

[...] Toda representação é composta de figuras e de expressões socializadas. Conjuntamente, uma representação social é a organização de imagens e linguagem, porque ela realça e simboliza atos e situações que se tornam comuns. [...] uma representação fala tanto quanto mostra, comunica tanto quanto exprime. No final das contas, ela produz e determina os comportamentos, pois define simultaneamente a natureza dos estímulos que nos cercam e nos provocam, e os significados das respostas a dar-lhes. Em poucas palavras, a representação social é uma modalidade de conhecimento particular que tem por função a elaboração de comportamentos e a comunicação entre indivíduos (MOSCOVICl, 1978, p.25).

Assim sendo, quando representamos, estamos revelando o que pensamos sobre o objeto, evocando o passado, mas com uma espécie de filtragem das informações recebidas, buscando a coerência necessária entre a percepção e a interpretação dessas informações que foram protegidas por nossa memória.

Diante desse pressuposto, para que o profissional se reconheça como um sujeito em constante processo de formação e cujo papel no âmbito do quadro da educação infantil não se restrinja às concepções de práticas automatizadas e mecânicas como dar mamadeira, dar banho, colocar para dormir entre outros aspectos relacionados à rotina, é necessário que ele seja capaz de ressignificar os sentidos dessas ações e, portanto, que seja capaz de se interrogar sobre sua prática cotidiana.

Nessa perspectiva, é necessário que haja, por parte do professor, a reflexão-açãoreflexão constante sobre sua prática, bem como a busca de conhecimentos específicos para a superação da visão assistencialista construída historicamente no segmento. Pois se a educação infantil é parte integrante do sistema educacional brasileiro é importante que os conteúdos e práticas desenvolvidos nas instituições sejam condizentes com proposta de formação da criança como sujeito integral, e que o professor esteja familiarizado com saberes necessários para o exercício da docência com bebês e crianças. 


\section{-Revista de Iniciação à Docência, v.6, n.2, 2021- \\ Publicação: dezembro, 2021 - ISSN 2525-4332}

A esse respeito, o pensamento de Paulo Freire contribui sobremaneira, lançando luz sobre a importância de o educador infantil legitimar seu papel profissional, rompendo com o senso comum social que, por vezes, insiste em representar de maneira paternalista sua figura docente. É o que se observa, por exemplo, na obra "Professora sim, tia não: cartas a quem ousa ensinar" (FREIRE, 1997), na qual Freire explica que o mote "professora-tia" é mais um capítulo da luta contra a tendência à desvalorização profissional representada pelo hábito, que se cristaliza por muitas décadas, de transformar a professora num parente postiço².

Para o educador, aceitar a identificação da figura de um professor a de um tio significa retirar algo fundamental do docente: sua responsabilidade profissional de que faz parte a exigência política por sua formação permanente. Com efeito, assinala Freire (1997):

[...] O que me parece necessário na tentativa de compreensão crítica do enunciado - professora, sim; tia, não -, se não é opor a professora à tia não é também identificá-las ou reduzir a professora à condição de tia. A professora pode ter sobrinhos e por isso é tia da mesma forma que qualquer tia pode ensinar, pode ser professora, por isso, trabalhar com alunos. Isto não significa, porém, que a tarefa de ensinar transforme a professora em tia de seus alunos da mesma forma como uma tia qualquer não se converte em professora de seus sobrinhos só por ser tia deles. Ensinar é profissão que envolve certa tarefa, certa militância, certa especificidade no seu cumprimento, enquanto ser tia é viver uma relação de parentesco. Ser professora implica assumir uma profissão, enquanto não se é tia por profissão. Se pode ser tio ou tia geograficamente ou afetivamente distante dos sobrinhos, mas não se pode ser autenticamente professora, mesmo num trabalho a longa distância, "longe" dos alunos (FREIRE, 1997, p. 9).

Nesse contexto, subjacente à rotulação tia, não está apenas uma perspectiva distorcida da tarefa profissional do educador, mas também um pensamento ideológico de alguns setores sociais, os quais guardam, de maneira velada, interesses de manutenção da ordem social vigente. Em outras palavras, acentua Freire (1997):

[...] Identificar professora com tia, o que foi e vem sendo ainda enfatizado, sobretudo na rede privada em todo o país, é quase como proclamar que professoras, como boas tias, não devem brigar, não devem rebelar-se, não devem fazer greve. Quem já viu dez mil "tias" fazendo greve, sacrificando seus sobrinhos, prejudicando-os no seu aprendizado? E essa ideologia que toma o protesto necessário da professora como manifestação de seu desamor aos alunos, de sua irresponsabilidade de tias, se constitui como ponto central em que se apoia grande parte das famílias com filhos em escolas privadas. Mas também ocorre com famílias de crianças de escolas públicas (FREIRE, 1997, p. 10).

Ao longo de sua obra Freire sublinhou a necessidade de que o educador conhecesse profundamente seu contexto histórico e social, admitindo que "os outros" estão, como ele, condicionados pela realidade dialeticamente permanente e mutável.

\footnotetext{
${ }^{2}$ Dentre as discussões levadas a efeito sobre esse tema, Freire destaca o trabalho "Professora Primaria mestra ou tia" de NOVAES (1984).
} 


\section{-Revista de Iniciação à Docência, v.6, n.2, 2021- \\ Publicação: dezembro, 2021 - ISSN 2525-4332}

Ressalta, ainda, a importância de o educador analisar criticamente a realidade social e as teorias dominantes mantenedoras do status quo, conforme adverte o educador:

\footnotetext{
[...] A ideologia do poder não apenas opaciza a realidade, mas também nos torna míopes, para não ver claramente a realidade. O seu poder é domesticante e nos deixa, quando tocados e deformados por ele, ambíguos e indecisos. Daí ser fácil entender a observação que uma jovem professora da rede municipal de São Paulo me fez, em conversa recente: "Em que medida certas professoras querem mesmo deixar de ser tias para assumir-se como professoras? Seu medo à liberdade as conduz à falsa paz que lhes parece existir na situação de tias, o que não existe na aceitação plena de sua responsabilidade de professoras". (FREIRE, 1997, p. 10).
}

Para Freire, o ser humano é sujeito ativo de transformação e não seu objeto. A estrutura social é obra dos seres humanos e, portanto, é sempre contraditória: envolve tanto os que pretendem mantê-la quanto os que, insatisfeitos, pretendem transformá-la. Há então um antagonismo constante entre os que querem e os que não querem a mudança. Moscovici também considera que há esse confronto quando explicita que sempre ocorrerá uma luta simbólica, objetiva e material entre maiorias e minorias. A mudança inicia-se numa problematização da consciência: da passagem do estado de "objeto" a sujeito. Esse dar-se conta de seu papel ativo na mudança é o processo de politização da consciência.

Tanto Freire quanto Moscovici advertem que a mudança depende, sempre, de um posicionamento crítico, inquieto, descontente e desejante, que questiona a ordem e a uniformidade de condutas e opiniões. A mudança é, então, sempre um processo permeado de tensões declaradas entre posições diferentes. Assim, a educação reflexiva, seja ela em qualquer segmento de ensino, não está voltada à adaptação, mas sim, à transformação.

\section{O estudo: 0 contexto e a coleta de dados}

Este estudo enquadra-se no que (MARCONI; LAKATOS, 2017) consideram como pesquisa qualitativa de abordagem etnográfica. O objetivo geral foi compreender como as professoras participantes do estudo se representam e como percebem as representações que a sociedade faz do trabalho do professor da educação infantil. Os sujeitos participantes foram quinze pedagogas concluintes de uma pós-graduação latosensu de um curso intitulado Linguagens da Infância. As participantes atuam como professoras de educação infantil, cuja faixa etária abrange desde os bebês até crianças de cinco anos.

A escolha das participantes foi motivado por dois fatores: primeiro por estarem concluindo uma especialização em seu campo de atuação o que denota interesse na profissionalização docente. O segundo fator deveu-se a autora deste texto ministrar uma das disciplinas do referido curso e ter tido contado por dez semanas com as participantes, o que favoreceu o olhar investigativo da autora sobre questões suscitadas 


\section{-Revista de Iniciação à Docência, v.6, n.2, 2021- Publicação: dezembro, 2021 - ISSN 2525-4332}

pelo grupo acerca das representações sociais e sua influência no trabalho dessas profissionais.

Ao término do curso as professoras foram convidadas a participar de um grupo focal. A reunião teve três horas de duração e foi gravada em áudio com o consentimento das participantes ${ }^{3}$. Os dados coletados nesse encontro serviram como corpus de análise para este estudo

Conforme Gatti (2012), a coleta por meio do método grupo focal envolve uma discussão informal, com um grupo de tamanho reduzido, cujo interesse é obter informações de caráter qualitativo, podendo ser um instrumento importante na compreensão dos processos de construção da realidade por determinados grupos sociais, bem como para o conhecimento de "representações, preconceitos, linguagem e simbologias que prevalecem em relação a determinadas questões nos grupos de pessoas pesquisadas" (GATTI, 2012, p. 9).

As perguntas desencadeadoras da discussão foram: há quanto tempo você atua na educação infantil? Como foi seu início na carreira? O que te motivou a fazer essa pósgraduação? Como você se vê profissionalmente hoje, após concluir o curso? Em sua opinião, como a sociedade vê o trabalho do professor de educação infantil?

Após a transcrição da discussão, deu-se início ao processo de análise. Foi utilizado como balizador deste estudo, a técnica de Análise de Conteúdo (BARDIN, 2016), cujas etapas são: pré-análise; exploração do material; tratamento dos resultados, inferência e interpretação.

As questões desencadeadoras da discussão no grupo focal serviram como base para criação das categorias, quais foram: como eu me vejo; como a sociedade me vê; percurso profissional; aprendizagens na pós-graduação. Para esse artigo, selecionamos alguns trechos dos relatos de duas categorias e os cotejamos com os estudos de Paulo Freire e de autores da teoria das representações sociais.

\section{Resultados e discussão}

Tendo por base o objetivo de conhecer as representações que as docentes têm sobre sua atividade profissional, bem como as representações que a sociedade faz ao trabalho do professor de educação infantil, selecionou-se para este artigo apresentar a análise de duas categorias: "Como eu me vejo" e "como a sociedade me vê".

- Categoria: Como eu me vejo

Nessa categoria, algumas participantes associaram o "ser professor da educação infantil" como o indivíduo que possui: vocação, que gosta de criança, desenvolve uma

\footnotetext{
${ }^{3}$ As participantes assinaram o Termo de Consentimento Livre Esclarecido para utilização de dados. Seus nomes foram alterados neste texto.
} 
relação maternal, sugerindo dessa forma, uma representação tradicional da profissão, enraizada no processo sócio-histórico e cultural do segmento do educador infantil. Tratase, conforme discutido, de um dos eixos mais arraigados e sustentadores desse componente representacional. Nas palavras das participantes:

[...] Para ser professora de criança precisa gostar muito dos pequenininhos, ter vocação, pois eles exigem dedicação e afeto [...] (Ana).

[...] Quando eu comecei a trabalhar, meu primeiro emprego foi numa creche. Mas não foi difícil, porque eu tratava os bebês do mesmo jeito que tratei meus filhos: com carinho e cuidado [...] eu me doava para eles [...] (Júlia).

[...] eu gosto de dizer que o papel de professora de pequeninos é igual a metáfora do laço: numa ponta estão os pais, na outra a gente e na soma dos dois, no meio do laço, está a criança. Então penso que a gente faz muito o papel da mãe [...] (Patrícia).

[...] além de gostar, precisa ter muita paciência. Não é fácil ser professora de criança, são poucos os que têm esse dom (Lúcia).

As expressões utilizadas pelas participantes permitem inferir que o senso comum, construído ao longo dos últimos anos, impôs uma representação sobre a função da professora na educação infantil "como uma pessoa responsável pelos cuidados básicos da criança - tarefa para a qual a afetividade é o maior atributo como: 'ter jeito', 'ter amor às crianças', 'gostar'” (CUNHA, 1999, p. 4). Tal representação pode ter proporcionado a identificação dessas educadoras com esse papel, pois nota-se como elas descrevem como é o "papel de professora de pequeninos".

A metáfora do laço utilizada no depoimento de Patrícia coloca o professor como uma extensão do papel da família e que ambos, professor e pais, têm a função de educar. Mas será que se trata do mesmo sentido de educar? Freire (1986) destaca que "existem graus de educação" e que essas ocorrem em diferentes ambientes sociais. A educação que ocorre na escola tem um caráter sistêmico e profissional. A tarefa do educador é de problematizar o objeto de conhecimento com intuito de possibilitar aos alunos um "exercício de pensar criticamente, tirando suas próprias interpretações do porquê dos fatos" (FREIRE, 1992, p. 52).

A visão paternalista do educador, conforme se observa nos depoimentos, é incorporada de maneira natural na mentalidade dessas professoras, o discurso delas contribui para reforçar o ideário comum que a sociedade tem desse profissional. Como assevera Moscovici (1978, p. 25), a representação social "produz e determina os comportamentos, pois define simultaneamente a natureza dos estímulos que nos cercam e nos provocam, e os significados das respostas a dar-lhes".

Ressalta-se, no entanto, que a crítica a essa representação de nada exclui a importância da afetividade na atuação docente. Conforme Freire (1997, p. 9), o profissional de educação de crianças pequenas possui uma tarefa que, sendo prazerosa, também é exigente de seriedade, de comprometimento, de preparação pedagógica, 
emocional e afetiva: "a tarefa de ensinar é uma tarefa profissional que, no entanto, exige amorosidade, criatividade, competência científica".

Para Freire a escola pode ser alegre e leve. Num espaço em que haja afetividade, a curiosidade tem condições de avançar para um estágio epistemológico, mesmo entre crianças muito pequenas, que aprendem, desde cedo, que podem e devem empregar toda a sua energia na busca de conhecer e que a descoberta do novo, depois do esforço, pode ser sumamente prazerosa. A escola alegre e leve, "[...] nada tem a ver com uma escola fácil, irresponsável. Pelo contrário, ela é cuidadosa, trabalha criticamente a disciplina intelectual da criança, estimulando-a e desafiando-a a engajar-se seriamente na busca do conhecimento" (FREIRE, 2001, p. 196).

A teoria das representações sociais ajuda a entender os motivos de as educadoras se representarem da maneira observada em seus depoimentos. De fato, é difícil incorporar o novo às ideias preexistentes e objetivar os novos conhecimentos tornandoos familiares, ancorando-os, no sentido de modificar as condutas consensuais reificadas pelo discurso do imaginário social.

Entretanto, como a representação não é estática, as mesmas professoras também revelam em seus discursos expressões que denotam profissionalidade, compromisso, autoformação - elementos que vão compondo um quadro de como elas também se percebem e se representam, como verificado nos trechos abaixo:

Sempre considerei que estudar era importante, mas ao longo desses dois anos eu fui percebendo como eu estava errando, como eu tinha que fazer coisas diferentes com as crianças (Júlia).

Eu me vejo dentro da sala de aula com uma responsabilidade muito grande. Porque a gente acaba sendo não só professora, mas também um pouco de mãe, por isso é extremamente importante avaliar a criança em suas necessidades de aprendizagem, porque nosso papel é voltado para o desenvolvimento educacional (Lúcia).

Eu sou professora da rede pública de uma comunidade carente. A maior parte deles não tem nem quintal para brincar, não tem alguém que brinque, que cante, que faça uma leitura de uma história. Então eu tomei um pouco dessa responsabilidade, de não deixar as crianças que passarem por minha sala, sair sem vivenciar experiências infantis. Esses momentos que são tão importantes também devem ser considerados como aprendizagem. Então, hoje eu me vejo como uma profissional que tenta valorizar a cultura da infância (Patrícia).

É possível depreender nesses depoimentos uma maior sensibilidade quanto ao discurso pedagógico atual, isto é, quanto ao discurso da "cultura da infância" delineado na Nova Base Nacional Comum Curricular - BNCC, conforme se observa:

[...] A Educação Básica deve visar à formação e ao desenvolvimento humano global, o que implica compreender a complexidade e a não linearidade desse desenvolvimento, rompendo com visões reducionistas que privilegiam ou a dimensão intelectual (cognitiva) ou a dimensão afetiva. Significa, ainda, assumir uma visão plural, singular e integral da criança, do adolescente, do jovem e do adulto - considerando-os como sujeitos de aprendizagem - e promover uma educação voltada ao seu acolhimento, reconhecimento e desenvolvimento pleno, nas suas singularidades e diversidades (BRASIL, 2017, p.14). 


\section{-Revista de Iniciação à Docência, v.6, n.2, 2021- \\ Publicação: dezembro, 2021 - ISSN 2525-4332}

A aparente contradição no discurso das participantes ocorre, provavelmente, pelo fato de elas estarem concluindo uma pós-graduação cuja concepção de educação infantil, bem como do papel do professor desse segmento, assemelha-se aos princípios da pedagogia libertadora proposta por Paulo Freire (1986), na qual se valoriza a análise crítica da educação tradicional visando à formação de uma consciência crítica. Tal pedagogia concebe professores e alunos como sujeitos do ato educativo e a relação dialógica autêntica como forma de aprender e atuar.

Assim, os processos de comunicação ao qual as educadoras estiveram expostas ao longo do curso concorrem ou pressionam para que apresentem em seus discursos uma visão comum da "cultura da infância". A esse respeito, Jodelet (2001) explica que fenômenos como esse ocorrem devido à pressão pela inferência, ou seja, pela necessidade de agir, de tomar posição ou de obter reconhecimento e adesão dos outros sujeitos do grupo. A pressão pela inferência promove o processo de objetivação, no qual ocorre um duplo esforço do sujeito. Esse transporta os elementos objetivos para o meio cognitivo atribuindo-lhes uma realidade tangível aproximada do universo do grupo de pertença.

Numa perspectiva parecida, Freire considera que o homem é capaz de romper com os papeis (ou representações) que lhe são atribuídos socialmente, por meio de um processo que classifica como transição. Para o educador:

Não há transição que não implique um ponto de partida, um processo e um ponto de chegada. Todo amanhã se cria num ontem, através de um hoje. De modo que o nosso futuro se baseia no passado e se corporifica no presente. Temos de saber o que fomos e o que somos, para saber o que seremos (FREIRE, 1983, p. 33).

[...] Nutrindo-se de mudanças, a transição é mais que as mudanças. Implica realmente na marcha que faz a sociedade na procura de novos temas, de novas tarefas ou, mais precisamente, de sua objetivação. (FREIRE, 1983, p. 65)

O conjunto de mudanças aos quais os sujeitos estão expostos, como é o caso das professoras deste estudo, mobilizam a reformulação das representações sociais. Ainda que o processo seja demorado, tais mudanças fazem com que a sociedade prossiga em busca de novos temas e da objetivação desses. A sociedade, constituída por suas crenças, valores, concepções, está em questionamento e reflexão constantes. Quando essas reflexões e mudanças provocam o rompimento do equilíbrio do pensamento vigente, as crenças e os valores decaem, surgindo novos em seu lugar. Esse período é chamado de transição.

Assim, pode-se concluir, que as participantes deste estudo não têm uma visão unilateral de si, pois estão no período de transição, tentando objetivar seu papel profissional.

- Categoria: como a sociedade me vê

A falta de valorização do professor de educação infantil foi recorrente nos 
depoimentos. Predomina a noção de que o profissional do segmento é menos reconhecido e valorizado, e que a educação voltada para essa etapa do não tem o mesmo prestígio que as demais etapas da escolarização:

Para o dia da reunião de pais eu e minhas colegas nos preparamos bastante, elaboramos uma pauta [...]. A gente queria que os pais compreendessem nossa proposta pedagógica. Não queríamos somente ficar mostrando fotos e filmagens dos filhos deles, mas discutir com eles, em que medida, nossas aulas estavam contribuindo para o desenvolvimento integral das crianças. Os pais foram chegando para a reunião e nós estávamos os recepcionando no pátio. A diretora da escola estava conosco. De repente, ela pega o microfone e diz: "sejam bem-vindos pais, dentro de alguns minutos as tias irão com vocês para as salas". Escutar, no alto-falante, a expressão 'tia' vinda da boca da própria diretora, foi horrível para mim. Naquele momento, toda minha segurança foi desmoronando. Entrei na sala com vontade apenas de mostrar fotos dos filhos deles. (Andréa).

No primeiro dia de aula desse ano, durante a reunião de pais, um pai falou: "então tia ...". Eu respondi: olha pais, eu quero deixar uma coisa bem clara aqui, eu não sou tia, eu fiz uma faculdade de quatro anos e agora estou me especializando para dar uma educação melhor para o filho de vocês. Alguém aqui estuda para ser tio? (Elisangela)

O não reconhecimento a que se referem as participantes não é apenas profissional, mas também social. Elas consideram que os professores de educação infantil ainda não alcançaram status de profissionais. Sobressai, desse modo, a ideia nuclear recorrente de que o professor desse segmento é aquele que desempenha funções maternas.

Quando a gente fala que é da educação infantil, nossos colegas e parentes não nos valorizam [...] as pessoas não entendem que a agente é educadora da infância (Sara).

Eu vivi esse dilema dentro da minha própria família. Quando eu me tornei professora da educação infantil, minha irmã chegou a me dizer "tanto estudo para ficar trocando fralda, para ser babá, pra cuidar do filho dos outros!?". Para esse servicinho você não precisava ter feito faculdade (Gisele).

Referir-se à educação infantil como um "servicinho" traz subjacente a representação de que o trabalho nesse segmento não tem relevância e que qualquer pessoa, sem qualquer preparação formativa, pode realizar essa atividade. Contrário ao encarar o trabalho do professor da educação infantil como sendo de menor prestígio social, Freire afirma:

[...] Lidamos com gente, com crianças, com adolescentes, ou adultos. Participamos de sua formação. Ajudamo-los ou os prejudicamos nesta busca. Estamos intrinsecamente a eles ligados no seu processo de conhecimento. Podemos concorrer com nossa incompetência, com nossa má preparação, com nossa responsabilidade para seu fracasso. Mas podemos também, com nossa responsabilidade, como nosso preparo científico e ou nosso gosto do ensino, com nossa seriedade e o nosso testemunho de luta contra as injustiças contribuir para que vão se tornando presenças marcantes no mundo. (FREIRE, 1997, p. 150)

Edenilza expõe em seu depoimento como se sente em relação ao tratamento que muitas vezes lhe é conferido: 
Eu me vejo como professora da educação infantil, que tem que estar o tempo todo tentando provar para sociedade que a gente é importante. Isso é uma ofensa [...] quem somos nós? As professoras? As tias, não é assim? Nós somos as tias, nós não somos valorizadas; muitas vezes pelas famílias, pelo grupo de trabalho, não somos valorizadas financeiramente. Não somos valorizadas no contexto geral da educação, do ser humano. Às vezes eu acho que isso revolta, tristeza [...].

Apesar de sofrer com a visão de desvalorização profissional, Edenilza não se resigna e não assume a representação de tia que lhe é atribuída socialmente, pois em outro momento da roda de conversa a educadora afirma:

Mas para mim isso é um incentivo para eu continuar, se é para provar, eu não vou provar, porque meus alunos precisam de mim integralmente ali com eles. Seu eu ficar o tempo todo tentando provar para os outros o que eu e meus alunos somos capazes juntos de construir, eu me torno uma pessoa frustrada, eu não chego a lugar nenhum. Então eu me vejo nessa condição, de deixar prá lá muitas coisas que a gente precisa para sobreviver e parar para pensar naquilo que realmente me satisfaz: que é eu ver o resultado lá na frente. Independentemente de a maioria das pessoas acharem que a gente não faz nada (Edenilza).

Opondo-se a essa representação, Paulo Freire adverte que o educador deve se mostrar persistente, assumindo-se como sujeito atuante no movimento de conscientização, da luta pela mudança e por uma educação como prioridade, conforme afirma: "os professores precisam continuar brigando, e muito. É preciso também, que a opinião pública entenda o direito e até o dever que os professores têm de lutar. [...]" (FREIRE, 2001, p. 245). Freire considera que existem diferentes maneiras de protestar, dentre elas está a inserção crítica, ou a tomada de consciência pelo indivíduo oprimido de sua realidade. Para o educador, não basta que o indivíduo seja consciente de que faz parte da sociedade, o mais importante é que este conheça o seu papel na coletividade e que seja capaz de questioná-lo a fim de produzir transformações.

[...] por isto inserção crítica e ação já são a mesma coisa. Por isso também é que o mero reconhecimento de uma realidade que não leve a esta inserção crítica (ação já) não conduz a nenhuma transformação da realidade objetiva, precisamente porque não é reconhecimento verdadeiro. (FREIRE, 1987, p. 38)

O protesto de Edenilza é potente, pois não se mantém no mero reconhecimento e acomodação da realidade, ao contrário, busca transformá-la por meio de sua formação continuada.

Numa perspectiva similar, outra participante do grupo de discussão relata:

Isso que a gente tem que ficar provando para as outras pessoas, eu acho que o principal é provar para nós mesmas que somos professoras. É a gente se valorizar e entrar no debate quando alguém vem questionar [...] eu acho que o essencial para isso é o que a gente tá fazendo agora, é a formação; é a gente ter o conhecimento pra gente conseguir debater [...] quando a gente começa a buscar nossa formação e aprimoramento, entendendo mais nossa posição como professora, $a$ gente tem mais bagagem para defender a nossa profissão, e até mesmo se valorizar primeiro; antes de pensar que as outras pessoas deveriam valorizar a gente (Paula).

Consciente de como a sociedade enxerga o professor da educação infantil, Paula entende que não há protesto com verbalismo, nem tão pouco com ativismo, mas sim com a práxis, ou seja, com reflexão e ação incidindo sobre as estruturas a serem 
transformadas. A esse respeito, Freire afirma:

\begin{abstract}
É exatamente esta capacidade de atuar, operar de transformar a realidade de acordo com finalidades propostas pelo homem à qual está associada sua capacidade de refletir, que o faz um ser da práxis. Se ação e reflexão, como constituintes inseparáveis da práxis são a maneira humana de existir, isto não significa, contudo, que não estão condicionadas, como se fossem absolutas, pela realidade em que está o homem (FREIRE, 183, p. 17).
\end{abstract}

A práxis é a reflexão do oprimido sobre seu mundo e a reação transformadora deste contra a realidade encontrada. Paula não naturaliza a visão que a sociedade tem a respeito do educador da primeira infância. Na Teoria das Representações Sociais, é na naturalização que se consuma o processo de objetivação. A imagem assume o lugar de realidade. Como bem descreve Moscovici (2003, p. 74) "a imagem do conceito deixa de ser um signo e torna-se a réplica da realidade, um simulacro [...] adquirindo uma existência quase física, independente".

Contudo, mesmo considerando que processos de influência podem assegurar estabilidade a representações específicas, como adverte Moscovici (2003), tais representações não são eternas, nem generalizáveis por si mesmas e podem apresentarse de um modo distinto em um mesmo grupo.

Assim, para que haja mudanças nas representações que a sociedade impõe ao educador da educação infantil, esses profissionais devem considerar sua práxis. Para que haja práxis, é essencial, que o indivíduo seja levado a tomar consciência de sua realidade para que, então, possa refletir sobre ela e, finalmente, questioná-la e transformá-la.

Indiscutivelmente, as representações que a sociedade faz sobre o trabalho do professor da educação infantil interferem nas relações e nas práticas pedagógicas. A despeito de todas as dificuldades que revelam enfrentar, as participantes não desistem da docência; ao contrário, buscam maneiras de se profissionalizar na área. Talvez a legitimação social seja um fator preponderante para que realizem um investimento em sua formação continuada. Por meio da profissionalização, buscam transformar a representação que a sociedade tem sobre o trabalho que realizam.

Os depoimentos sugerem que as docentes estão num constante enfrentamento de uma concepção que as diminui como profissionais. Percebe-se um alto grau de comprometimento pessoal de cada educadora, que reconhece a complexidade da profissão e a importância de uma formação adequada da área. As declarações revelam, ainda, o desejo de reconhecimento da educação infantil como uma etapa da educação básica.

O conjunto dos depoimentos revela que essas educadoras vivem no que Freire (2000) considera "situações-limite", ou seja, as barreiras que o ser humano encontra em sua caminhada, diante das quais pode assumir várias atitudes, como se submeter a elas ou, então, vê-las como obstáculos que devem ser vencidos. Diante dessas barreiras, o indivíduo pode unir esperança com a prática e agir para que a situação se modifique ou 


\section{-Revista de Iniciação à Docência, v.6, n.2, 2021- \\ Publicação: dezembro, 2021 - ISSN 2525-4332}

simplesmente se deixar levar pela desesperança. Para enfrentar situações-limite são necessários os chamados "atos-limite", termo usado por Freire para designar as atitudes assumidas a fim de se romper com as situações-limite. Esses atos são necessários para que se possa atingir o inédito-viável:

Nas situações-limite, mais além das quais se acha o "inédito viável", às vezes perceptível, às vezes não, se encontram razões de ser para ambas as posições: a esperançosa e a desesperançosa. Uma das tarefas do educador ou educadora progressista [...] é desvelar as possibilidades, não importam os obstáculos, para a esperança (FREIRE, 1992, p. 6).

Para o educador, a esperança é a crença no sonho possível, desde que aqueles que fazem a história assim o queiram. Essa é a crença que acompanha as educadoras participantes deste estudo.

\section{Considerações finais}

De maneira geral, os currículos de Pedagogia ainda oferecem pouco espaço para a reflexão e para o processo de formação docente. Professores iniciam atividades sem saber direito o que é ser um profissional da educação infantil, que conjunto de saberes e práticas ela envolve, que identidade profissional constitui (GATTI, BARRETO, 2009). Se os cursos de Pedagogia não contemplam como deveriam a educação infantil, isso, de alguma forma, talvez influenciem as representações negativas que os próprios professores possuem sobre a área.

A desvalorização da profissão constitui um dos maiores obstáculos ao desenvolvimento da profissionalidade. Investir em uma formação que contemple as especificidades dessa fase pode levar a uma mudança nesse olhar revestido de negatividade sobre o trabalho do educador infantil. Nas palavras de Freire:

É preciso que haja luta, que haja protesto, que haja exigência e que os responsáveis, de maneira direta ou indireta, pela tarefa de formar entendam que formação é permanente. Não existe formação momentânea, formação do começo, formação do fim de carreira. Nada disso. Formação é uma experiência permanente, que não para nunca. (FREIRE, 2001, p. 245)

Para pensar em alcançar qualidade na educação, em qualquer que seja o segmento de ensino, há de se ter como ponto de partida uma política de valorização, de formação e de qualificação do professor, o que implica criar melhores condições de trabalho, reconhecer e valorizar a profissão e, sobretudo, uma remuneração adequada.

Para garantir uma prática que seja efetivamente coerente no compromisso com as crianças, é preciso que o educador se assuma como tal e lute por seus direitos como profissional. A educação infantil (também) exige seriedade e profissionais formados especificamente para atender a uma fase específica do desenvolvimento humano, e que não se confundem com as relações familiares de parentesco. É imprescindível que a professora, representada como tia afetiva e paciente, dotada de um dom maternal inato, 
sendo guiada somente pelo amor e pela intuição, dê lugar ao profissional da educação, com estudos específicos que abrangem o ser, o saber, o conhecer e o conviver da e na ação docente (FREIRE, 1997). Educação infantil não é campo para amadorismo.

\section{Referências}

ALTET, Marguerite.; PERRENOUD, Philippe; PAQUAY, Léopold. A profissionalização dos formadores. São Paulo: Artmed Editora, 2003.

AZEVEDO, Heloisa Helena Oliveira; SCHNETZLER, Roseli Pacheco. O binômio cuidareducar na educação infantil e a formação inicial de seus profissionais. In: Reunião anual da ANPED, 28., 2005, Caxambu. Anais... Caxambu: ANPED, 2005. Disponível em <https://www.anped.org.br/sites/default/files/gt071011int.pdf > Acesso em 06/2021.

BARDIN, Laurence. Análise de conteúdo. São Paulo: Edições 70, 2016.

BRASIL. Ministério da Educação; Secretaria de Educação Básica; Base Nacional Comum Curricular. Brasília: MEC, 2017.

CUNHA, Maria Isabel. Profissionalização docente: contradições e perspectivas. In.: VEIGA, Ilma Passos; CUNHA, Maria Isabel (Org.). Desmistificando a profissionalização do magistério. Campinas, SP: Papirus, 1999.

FREIRE, Paulo. Educação e Mudança. $12^{\text {a }}$ ed. Rio de Janeiro: Paz e Terra, 1983.

FREIRE, Paulo. Educação como prática da liberdade. Rio de Janeiro: Paz e Terra, 1986.

FREIRE, Paulo. Pedagogia do Oprimido. 17ª ed. Rio de Janeiro: Paz e Terra, 1987.

FREIRE, Paulo. Extensão ou comunicação? 10ª ed. Rio de Janeiro: Paz e Terra, 1992.

FREIRE, Paulo. Professora sim, tia não: cartas a quem ousa ensinar. São Paulo: Editora Olho d'Água, 1997.

FREIRE, Paulo. Pedagogia dos sonhos possíveis. São Paulo: Editora Unesp, 2001.

GATTI, Bernadete A. Grupo focal na pesquisa em ciências sociais e humanas. Brasília: Liber Livro, 2012.

GATTI, Bernadete A.; BARRETO, Elba Sá (Org.). Professores do Brasil: impasses e desafios. Brasília: Unesco, 2009.

JODELET, Denise. Representações sociais: um domínio em expansão. In.: JODELET, Denise. (org.). As representações sociais. Rio de Janeiro: EdUerj, 2001.

Kuhlmann Moysés Jr. Infância e educação infantil: uma abordagem histórica. Porto Alegre: Mediação, 2007.

MARCONI, Marina A.; LAKATOS, Eva Maria. Metodologia Científica. $7^{\mathrm{a}}$ ed. São Paulo: Atlas, 2017.

MOSCOVICI, Serge. A representação social da psicanálise. Rio de Janeiro: Zahar, 1978.

MOSCOVICI, Serge. Representações Sociais: Investigações em psicologia social. $4^{\mathrm{a}}$ ed. Petrópolis: Vozes, 2003. 
-Revista de Iniciação à Docência, v.6, n.2, 2021-

Publicação: dezembro, 2021 - ISSN 2525-4332

NOVAES, Maria Eliana. Professora primária: mestra ou tia São Paulo: Cortez, 1992.

$* * *$

Recebido: 16.07.2021

Aprovado: 17.11.2021 